\title{
28 Research Square \\ Principle and Control of Active Engine Mount Based on Magnetostrictive Actuator
}

\section{Zhi-Yuan Si}

Hefei University of Technology

Xianxu BAl ( $\boldsymbol{\sim}$ bai@hfut.edu.cn )

Hefei University of Technology https://orcid.org/0000-0003-4477-8335

\section{Li-Jun Qian}

Hefei University of Technology

\section{Peng Chen}

Guangzhou Automobile Research and Design Center

\section{Original Article}

Keywords: Terfenol-D rod, x-LMS, Sage-Husa Kalman filter, Semi-active control, Active mount controller

Posted Date: September 16th, 2020

DOI: https://doi.org/10.21203/rs.3.rs-76211/v1

License: @ (i) This work is licensed under a Creative Commons Attribution 4.0 International License. Read Full License 


\section{Abstract}

The engine mount system affects the automobile NVH performance. Active mounts would achieve excellent vibration isolation and relative displacement control performance in a broad frequency bandwidth by outputting controlled force to the mounting system. The actuator and control method of the active mounts determine the system performance. In this paper, an active mount based on the smart material - Terfenol-D rod is proposed, which mainly includes three parts: rubber spring, magnetostrictive actuator (MA), and hydraulic amplification mechanism. Dynamic model of the active mount is correspondingly established. A state feedback control method based on $\mathrm{x}$-LMS algorithm is proposed as well. Specifically, with the consideration of the unmeasurable state parameters in the active mounting system, an x-LMS state feedback controller with the system state as the reference signal is constructed by employing Sage-Husa Kalman filter to realize the state estimation of the active mounting system. Then a detailed analysis of the proposed control method is conducted, with deriving iterative formula of tap-weight vector. Sequentially, the problem of the dependence on the excitation signal in the x-LMS algorithm is addressed. The feasibility and capability of the proposed control method are verified and evaluated by simulation of a two-degree-of-freedom active mounting system.

\section{Full Text}

This preprint is available for download as a PDF.

\section{Figures}

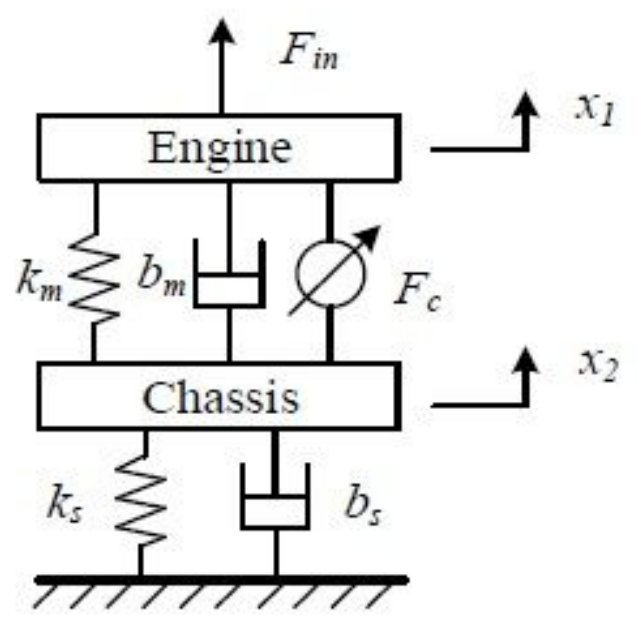

\section{Figure 1}

Two-degree-of-freedom active mounting system model 


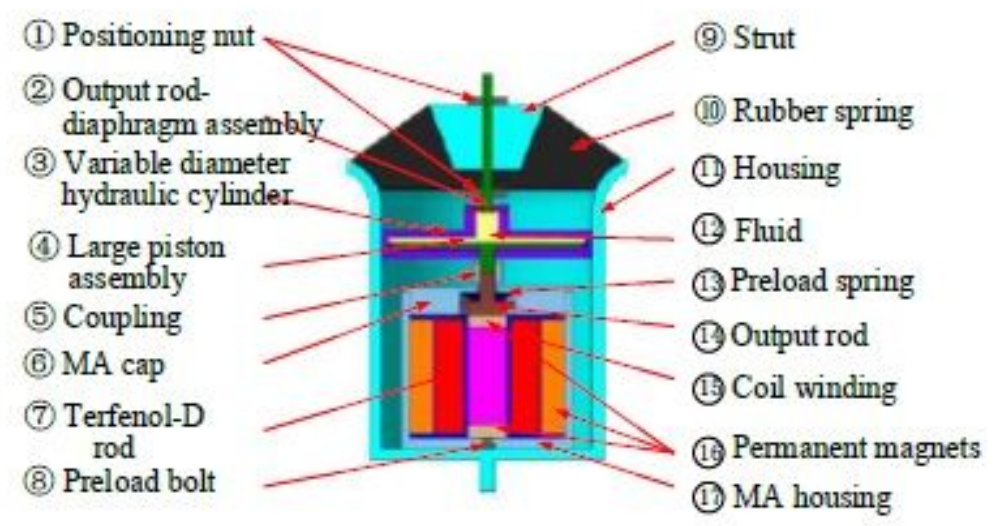

(a)

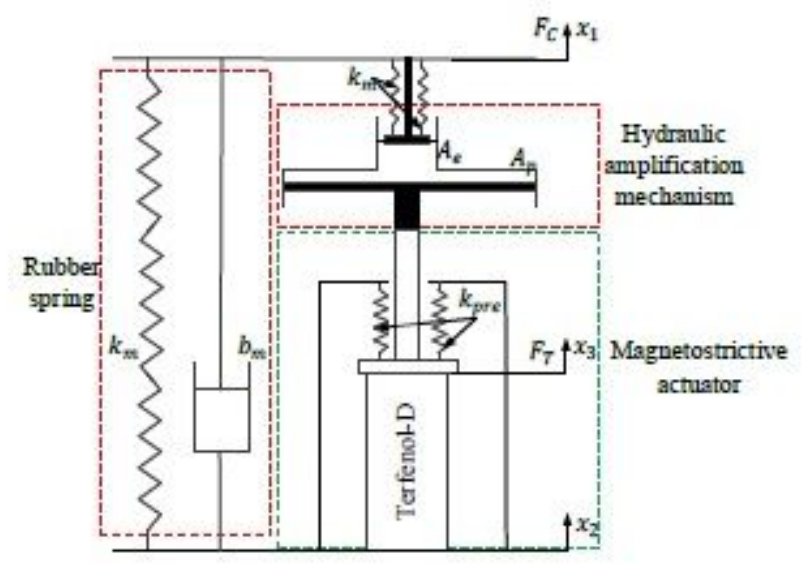

(b)

\section{Figure 2}

The proposed active mount: (a) the configuration and (b) the principle 


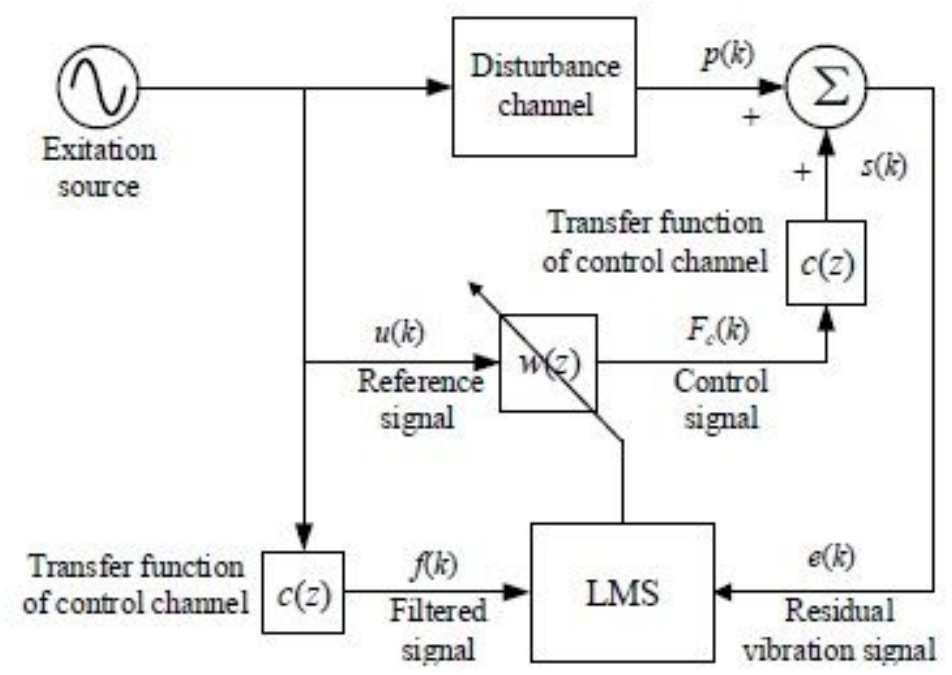

(a)

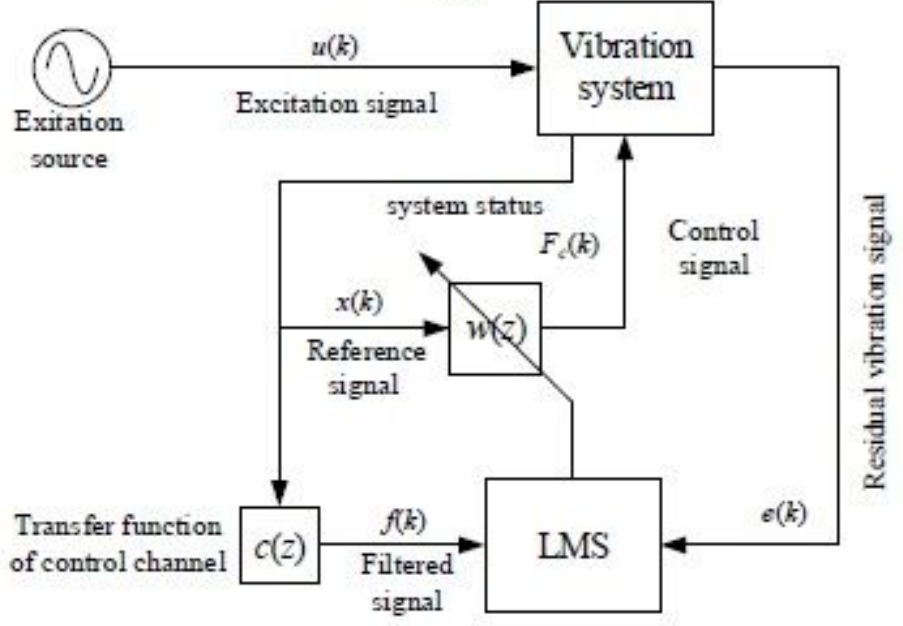

(b)

\section{Figure 3}

The control diagram: (a) x-LMS algorithm [9] and (b) x-LMS algorithm with state feedback

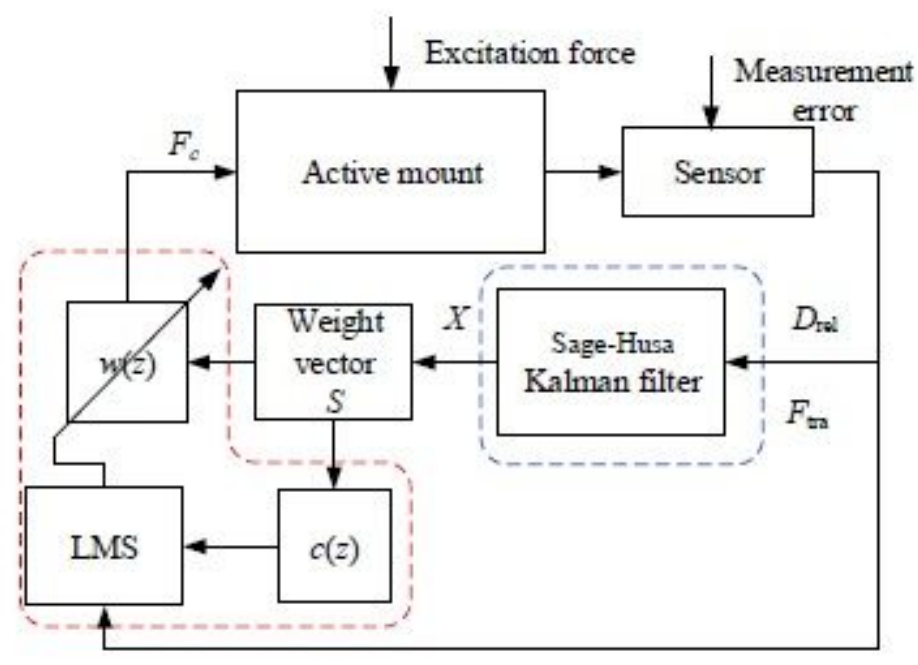

Figure 4 
Control principle of the active mounting system

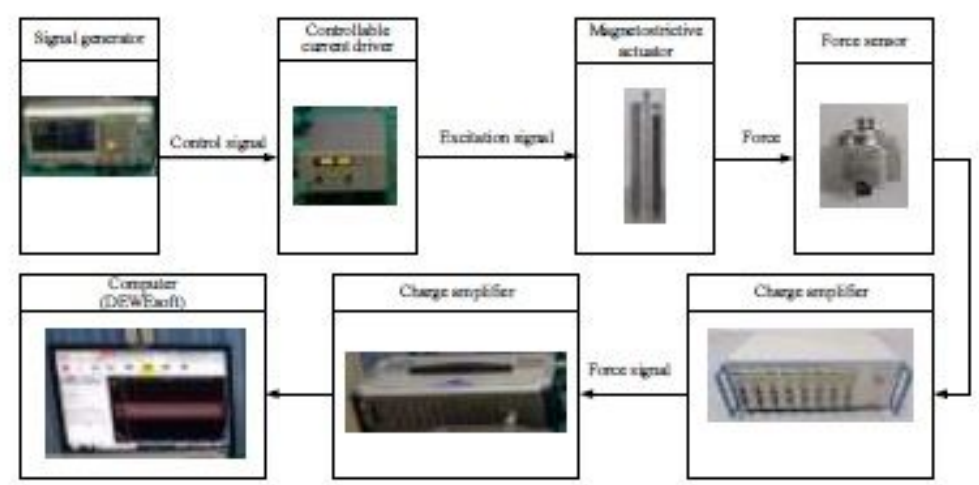

Figure 5

Dynamic force experiment platform of the MA

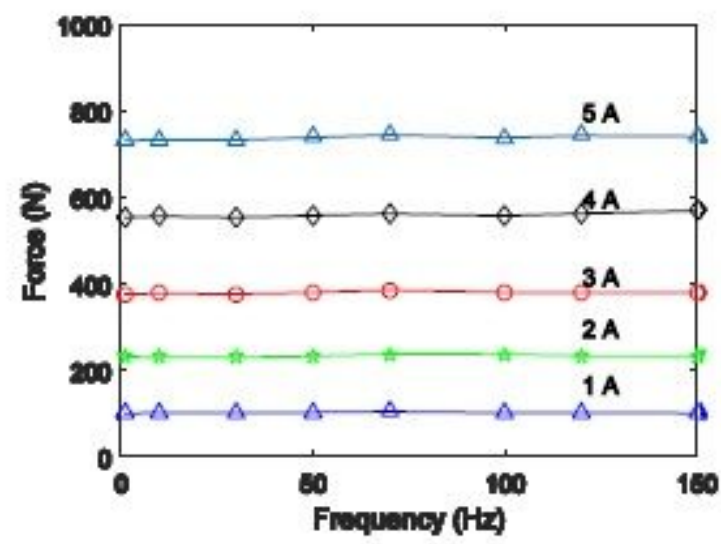

Figure 6

Dynamic force test results of the MA

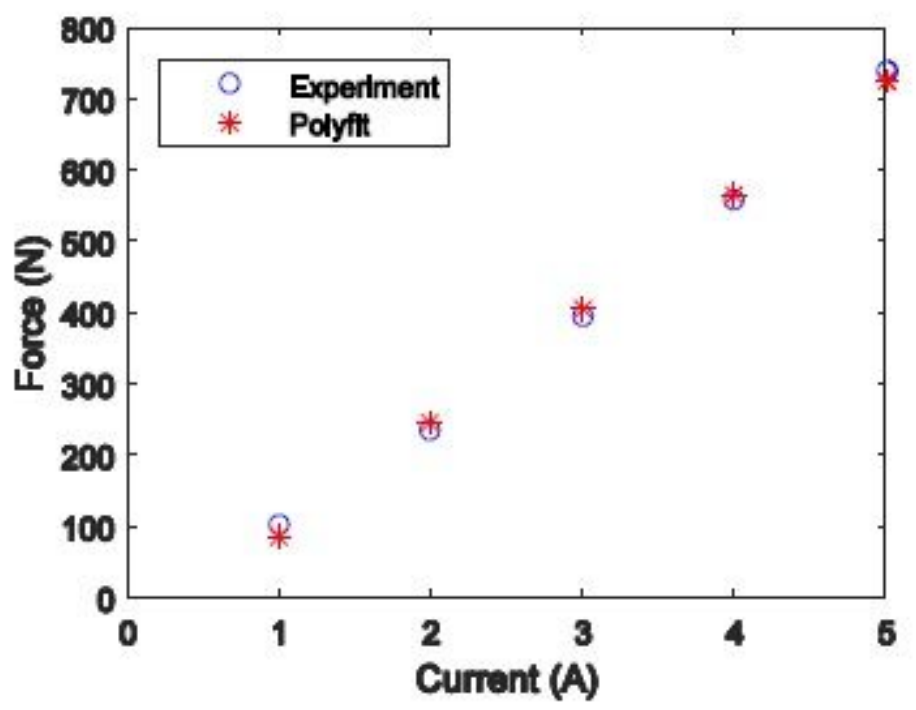


Figure 7

Output force-current relationship of the MA

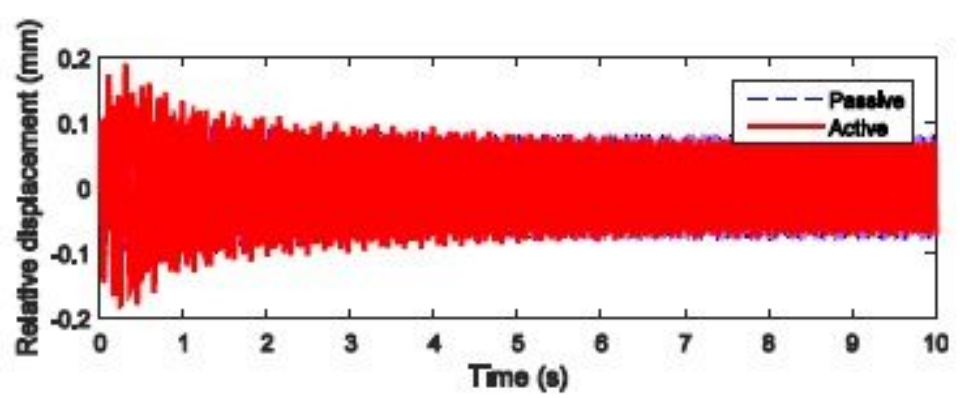

(a)

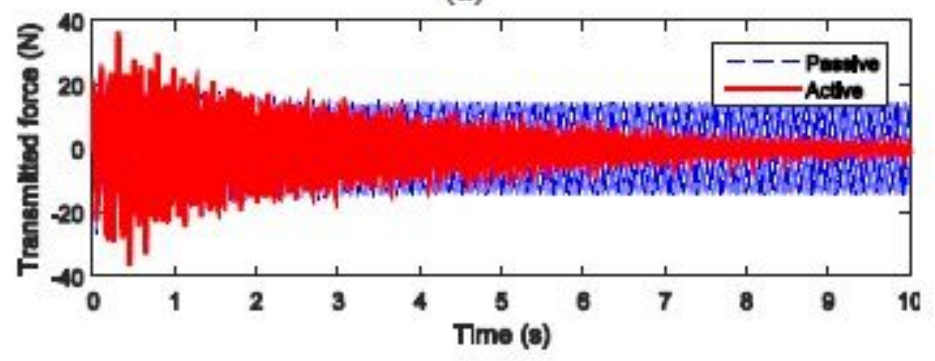

(b)

\section{Figure 8}

Comparison results of active mount and passive mount at the engine speed of $750 \mathrm{r} / \mathrm{min}$ : (a) the relative displacement and (b) the transmitted force 


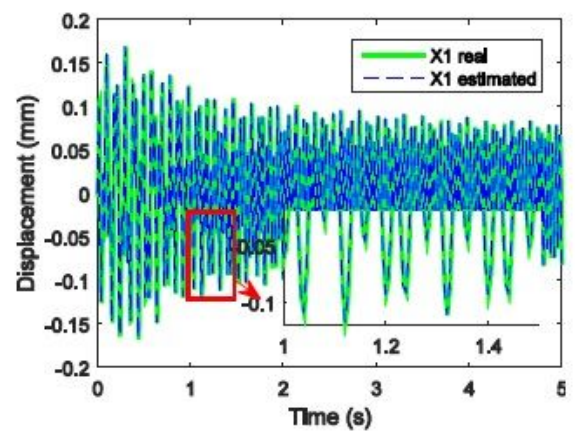

(a)
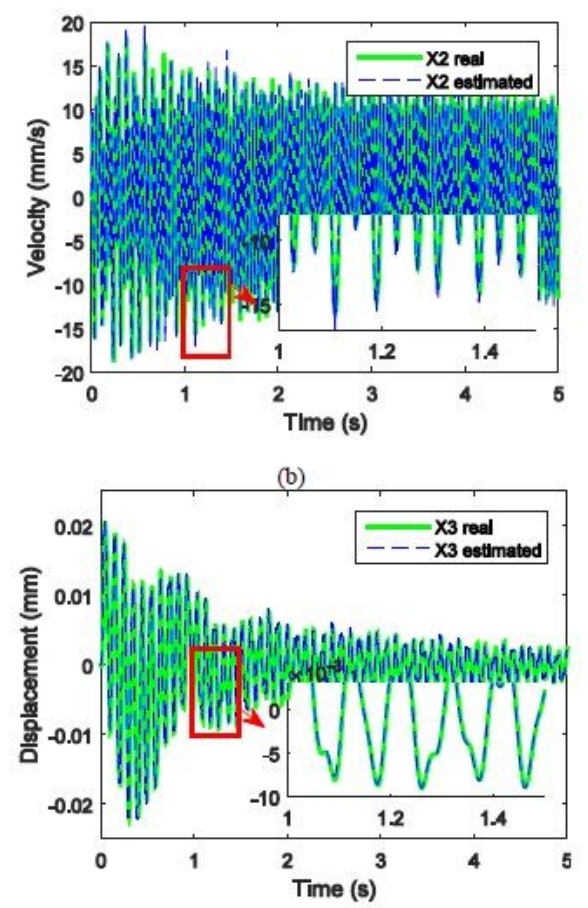

(c)

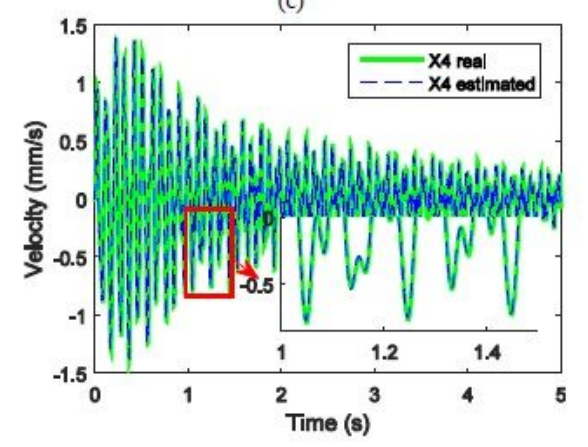

(d)

\section{Figure 9}

Comparison between estimated system state and real system state at the engine speed of $750 \mathrm{r} / \mathrm{min}$ : (a) $X 1$ : engine displacement, (b) $X 2$ : engine velocity, (c) $X 3$ : sprung mass displacement, and (d) $X 4$ : sprung mass velocity 


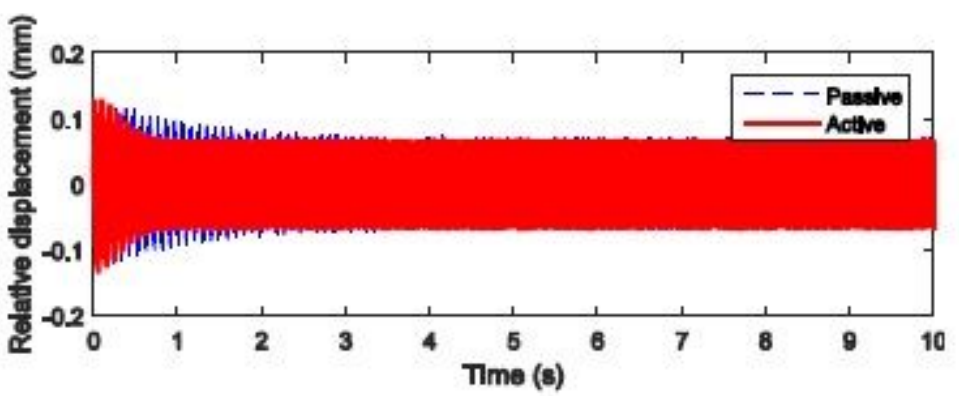

(a)

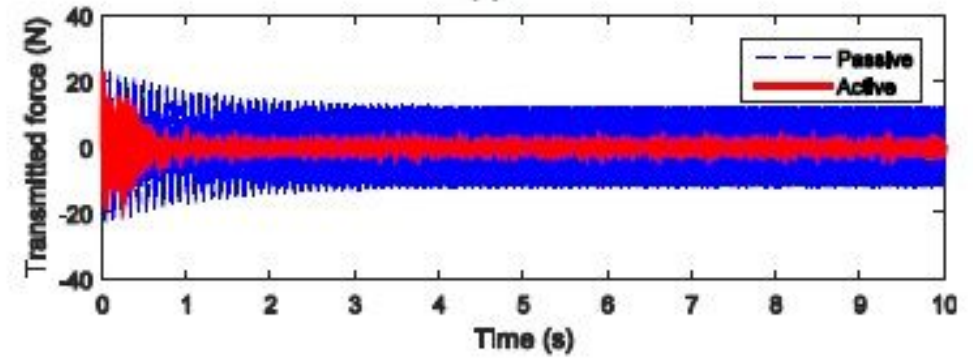

(b)

\section{Figure 10}

Comparison results of active mount and passive mount at the engine speed of $3000 \mathrm{r} / \mathrm{min}$ : (a) the relative displacement and (b) the transmitted force 

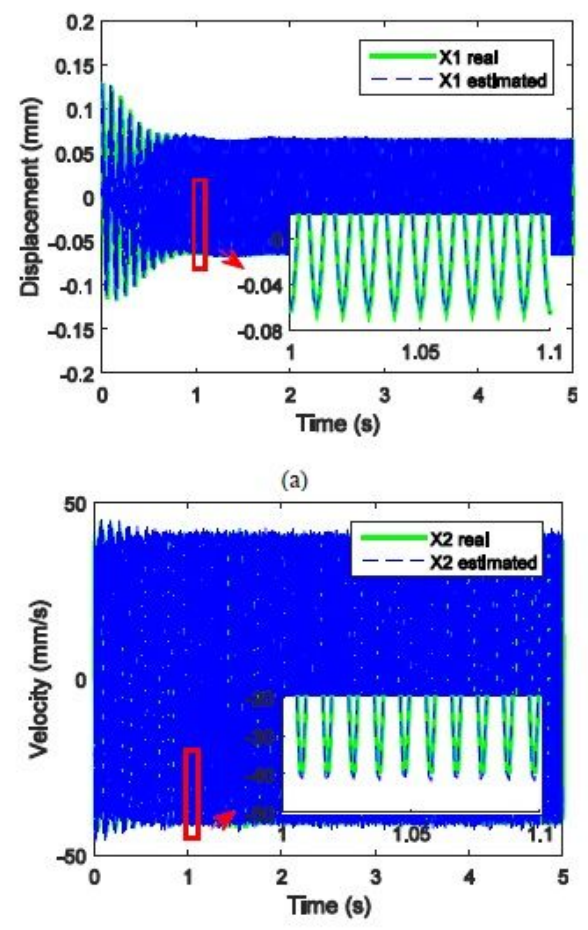

(b)

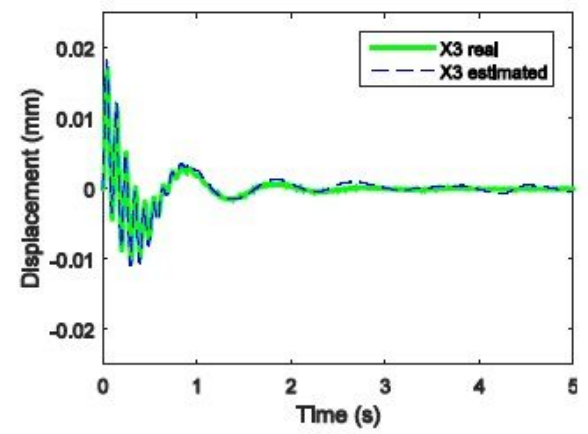

(c)

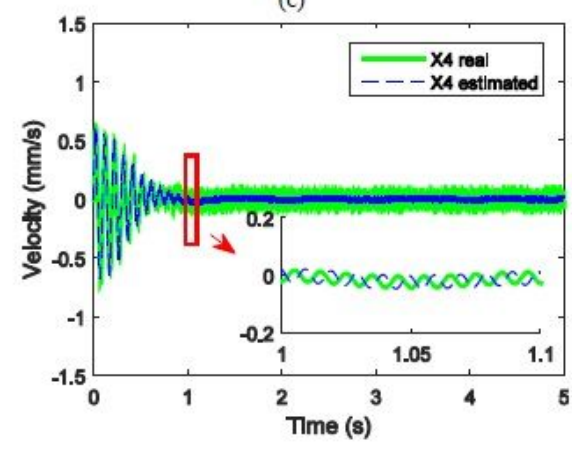

(d)

\section{Figure 11}

Comparison between estimated system state and real system state at the engine speed of $3000 \mathrm{r} / \mathrm{min}$ : (a) $X 1$ : engine displacement, (b) $X 2$ : engine velocity, (c) $X 3$ : sprung mass displacement, and (d) $X 4$ : sprung mass velocity 


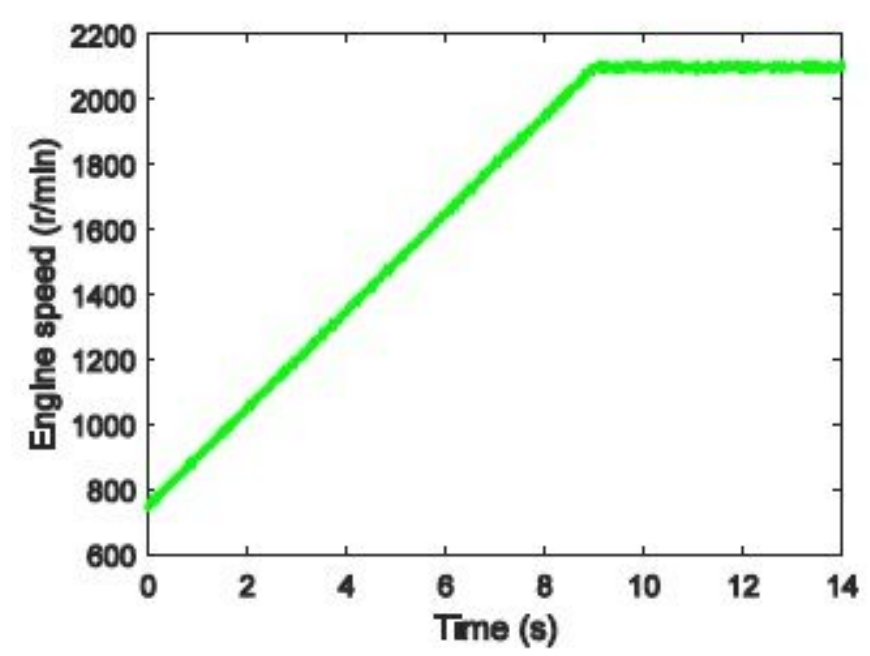

Figure 12

The process of variable engine speed

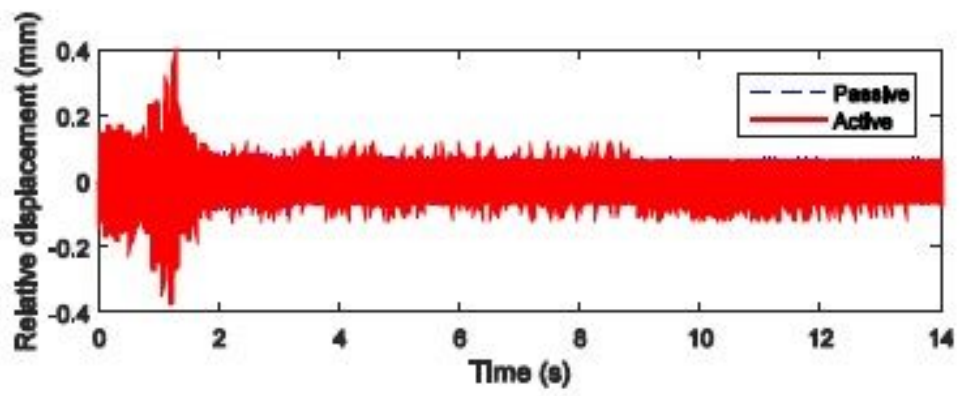

(a)

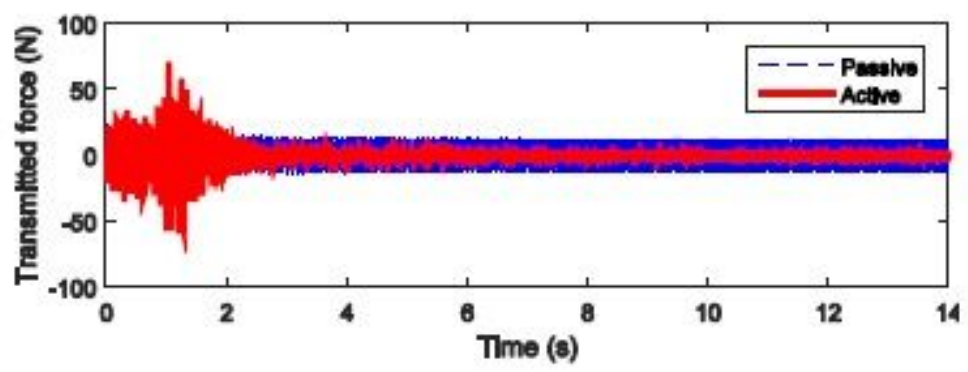

(b)

\section{Figure 13}

Comparison results of active mount and passive mount under variable engine speed conditions (engine speed increased from $750 \mathrm{r} / \mathrm{min}$ to $2100 \mathrm{r} / \mathrm{min}$ ): (a) the relative displacement and (b) the transmitted force 

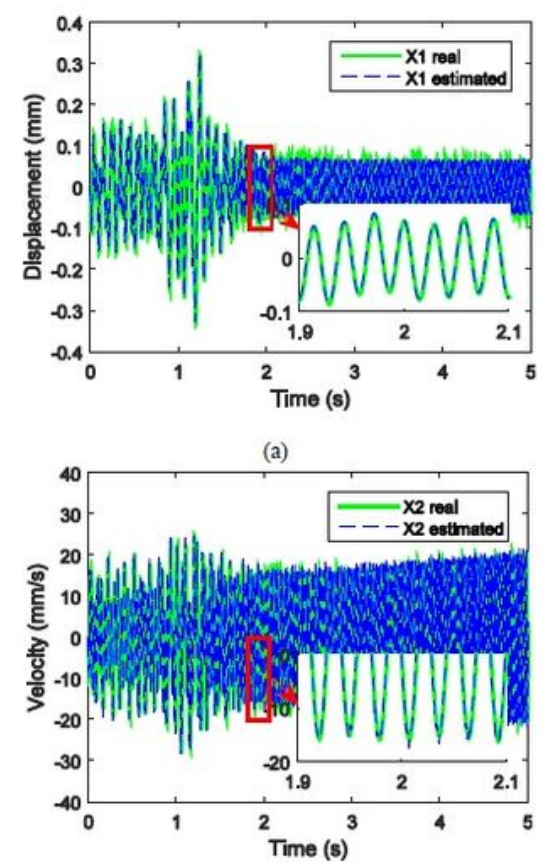

(b)
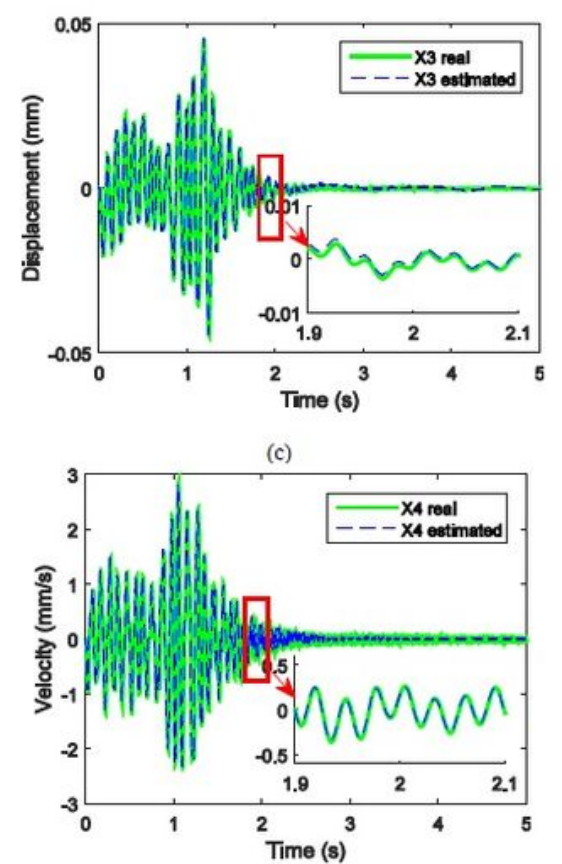

(d)

\section{Figure 14}

Comparison between estimated system state and real system state under variable engine speed condition (engine speed increased from $750 \mathrm{r} / \mathrm{min}$ to $2100 \mathrm{r} / \mathrm{min}$ ): (a) $X 1$ : engine displacement, (b) $X 2$ : engine velocity, (c) $X 3$ : sprung mass displacement, and (d) $X 4$ : sprung mass velocity 